\title{
THE POTENCY OF CHITOSAN AS AN ELICITOR ON ANTIBACTERIAL ACTIVITY OF Streptomyces sp. GMR-22 AGAINST HISTAMINE-PRODUCING BACTERIA
}

\author{
Mohamad Aji Ikhrami ${ }^{1}$, Jaka Widada ${ }^{2}$, Indun Dewi Puspita ${ }^{1}$ and Masagus Muhammad \\ Prima Putra $^{1^{*}}$ \\ ${ }^{1}$ Fish Product Technology, Department of Fisheries, Faculty of Agriculture, Universitas Gadjah \\ Mada, Jl. Flora gedung A4, Bulaksumur Yogyakarta 55281 \\ ${ }^{2}$ Department of Agricultural Microbiology, Faculty of Agriculture, Universitas Gadjah Mada, Jl. \\ Flora gedung A4, Bulaksumur Yogyakarta 55281 \\ *Corresponding author, e-mail: primaputra@ugm.ac.id
}

\begin{abstract}
Streptomyces is a Gram-positive bacteria that produces the largest secondary metabolite compounds. The results of whole-genome sequence analysis showed that Streptomyces can carry more than 30 Biosynthetic Gene Clusters (BGC) encoding secondary metabolites that have the potential to be explored in the exploration for new bioactive compounds. However, not all BGC can be expressed in the laboratory scale and requires a specific activation method. This study aims to explore the potential of chitosan as an elicitor compound to activate and or increase the antibacterial activity of Streptomyces sp. GMR-22 was tested against histamine-producing bacteria (HPB) Morganella morganii TK7 and Citrobacter freundii CK1. Chitosan was added to the fermentation medium with the final concentration of 250,500 , and $750 \mu \mathrm{g} / \mathrm{ml}$ while without the addition of chitosan used as control. Fermentation was carried out for 10 days at room temperature, with constant agitation $200 \mathrm{rpm}$. The supernatant was separated by centrifugation at $3500 \mathrm{rpm}$ for 15 minutes, then fractionation with ethyl acetate, concentrated by vacuum rotary evaporator, and freeze-dried. The test for antibacterial activity was carried out by the microdilution method with an extract concentration of $100 \mathrm{mg} / \mathrm{ml}$. The test results of the microdilution method showed that the addition of chitosan successfully increases the antibacterial activity with the highest activity shown by the water fraction of $250 \mu \mathrm{g} / \mathrm{ml}$ addition of chitosan which effective in inhibiting the growth of Morganella morganii TK7 and Citrobacter freundii CK1 by 97,29\% and 97,92\% respectively.
\end{abstract}

Key words: antibacterial, histamine-forming bacteria, elicitor, chitosan, Streptomyces sp. GMR- 


\section{INTRODUCTION}

Streptomyces is a group of filamentous Gram-positive bacteria belonging to the Actinomycetes phylum. These bacteria can be found in nature in various types of habitats such as the sea, soil, and in symbiosis with insects, plants and marine sponges (Cheng et al., 2015). Streptomyces is one type of potential bacteria that has produced nearly two-thirds of the antibiotic compounds that have been discovered and used to date (Procópioa et al., 2012). Several types of secondary metabolite compounds produced by Streptomyces include antifungal, anticancer, antiviral, and other antibiotics (Azerang \& Soroush, 2017). One of the Streptomyces species that has a large potential for bioactive compounds production is Streptomyces sp. GMR-22 which was isolated from soil samples in Wanagama Forest, Gunungkidul, Yogyakarta (Nurjasmi et al., 2009). Several studies have been conducted to detect the presence of bioactive compounds produced by Streptomyces sp. GMR-22 includes antifungal activity (Alimuddin et al., 2011) and antiviral (Mentari et al., 2019).

The secondary metabolite compounds that can be produced by Streptomyces are encoded by various types of protein coding genes that are located close to each other. These gene groups are called gene clusters and are located on chromosomes in the cell nucleus. Based on the analysis of genome mining using the AntiSMASH 3.0 program conducted by Herdini et al., (2017), Streptomyces sp. GMR-22 was reported to have around 63 types of biosynthetic gene clusters. However, Abdelmohsen et al. (2015) explained that the major gene clusters encoding secondary metabolites of this bacterial group were a little difficult to express under laboratory conditions. Streptomyces coelicolor A3 (2) was reported to have 29 types of BGC (Bentley et al., 2003), but only 6 types of BGC were expressed on a laboratory scale (Rutledge \& Challis, 2015). The other gene clusters that are not expressed named as silent or cryptic. Several strategies can be done to activate the silent gene cluster includes co-culture (Onaka, 2017), heterologous expression (Matsuda et al., 2017), ribosome engineering (Thong et al., 2018) and elicitation (Tyurin et al., 2018). Elicitation is one of the silent gene cluster activation methods by adding elicitor compounds to influence the expression of secondary metabolites. Elicitor is a compound that has the ability to stimulate changes in the production of secondary metabolites in cells (Abdelmohsen et al., 
2015). Several elicitor compounds reported have the potential to stimulate the expression of secondary metabolites by bacteria, namely ethanol; dimethylsulfoxide (DMSO) (Pettit, 2011); N-acetylglucosamine (NAG) (Rigali et al., 2008; Nazari et al., 2013); and chitin (Nazari et al., 2013).

Nazari et al. (2013) reported that the addition of chitin and $\mathrm{N}$-acetylglucosamine to the Streptomyces coelicolor A3 (2) culture resulted in an increase in the expression of antibiotics encoded by the Act, Red, Cpk cluster genes. Moreover, Rigali et al. (2008) also reported an increase in the expression of the production of the antibiotics undecylprodigiosin (Red) and actinohordin (Act) in the culture of Streptomyces coelicolor A3 (2) supplemented with $\mathrm{N}$ acetylglucosamine. However, research related to the application of chitosan as an elicitor compound to influence the expression of BGC in the production of Streptomyces secondary metabolites has not been reported. Chitosan is a chitin derivative compound that has undergone a deacetylation reaction.

Despite of the already reported bioactive compound produced by Streptomyces sp. GMR-22, information regarding the antibacterial activity has not been done yet. This study aim to observe the potency of chitosan as an elicitor compound to increase and or activate Streptomyces antibacterial compounds. Antibacterial test is carried out on histamine-producing bacteria (HPB) which is one of the pathogenic bacteria in fishery products. HPB produce histamine compounds that is toxic at certain concentrations. Apart from being able to trigger the formation of histamine, this group of bacteria is also reported to have various types of virulence factors that can be dangerous. Citrobacter freundii as one of HPB is also reported to cause food poisoning and diarrhea and can produce several toxic compounds such as Shiga-like toxins and heat-stable toxins (Liu et al., 2020).

\section{MATERIAL AND METHODS}

\section{Material}

Autoclave (Hirayama HVE-50), oven (Eyela NDO-451SD), orbital shaker (Ohaus), showcase chiller (Sanyo SRD180F), freezer (Sanyo MDF-U3333), vortex mixer (Ohaus), single beam spectrophotometer (Hanon $13 \mathrm{UV} / \mathrm{Vis}$ ), hot plate stirrer (Labnet PC-420D; Thermo Scientific SP88857107), micropipette (Ohaus), centrifuge (Corning 6766-HS), rotary evaporator, analytical balance (Shimidzu BX-320D) microtip, microtube, magnetic stirrer, petridish, inoculation 
needle, bunsen burner, cuvette (Brand $1.5 \mathrm{nl}$, semi-micro), measuring cup, test tube, propipet, falcon tube, vial tube, erlenmeyer, $\mathrm{pH}$ meter, fume hood, tweezers, separating funnel, needle ose, inoculation needle, drigalsky, magnetic stirrer, tweezers, measuring pipette, tip (white, yellow, and blue), microtube, laminar flow, yeast extract (Merck), glacial acetic acid, 70\% alcohol, ethyl acetate, antimicrobial susceptibility disk (Oxoid), cotton and gauze.

\section{Bacterial isolate and fermentation media}

Malt extract (Oxoid), dextrose (Oxoid), soluble starch (Merck), $\mathrm{KNO}_{3}$ (Merck), $\mathrm{K}_{2} \mathrm{HPO}_{4}$ (Merck), $\mathrm{MgSO}_{4} .7 \mathrm{H}_{2} \mathrm{O}$ (Merck), $\quad \mathrm{FeSO}_{4} .7 \mathrm{H}_{2} \mathrm{O} \quad$ (Merck), $\mathrm{NaCl}$ (Merck), bacteriological agar (Oxoid), Tryptic soya broth (Merck), Tryptic soya agar (Merck), medical grade chitosan (PT. Biotech Surindo), Streptomyces sp. GMR-22 (collection of Microbial Physiology Laboratory, Department of Agriculture Microbiology, Faculty of Agriculture UGM), and BPH Citrobacter freundii CK1, and Morganella morganii TK7 (collection of Fisheries Product Quality and Safety Laboratory, Department of Fisheries, Faculty of Agriculture UGM).

\section{Methods}

\section{Isolate refreshment}

Isolate Streptomyces sp. GMR-22 from glycerol stock stored in frozen conditions at $-23^{\circ} \mathrm{C}$ was inoculated on yeast extract malt extract agar medium (yeast extract $0.4 \%$; malt extract $1 \%$; dextrose $0.4 \%$; and agar 2\%) and incubated at room temperature for \pm 5 days. The histamineforming bacteria (BPH) used were Citrobacter freundii CK1, and Morganella morganii TK7 from glycerol stock stored in frozen conditions at $-23^{\circ} \mathrm{C}$ inoculated on tryptone soy agar (TSA) medium then incubated at $37^{\circ} \mathrm{C}$ for \pm 24 hours.

\section{Preparation of chitosan solution}

Preparation of chitosan stock solution was carried out by dissolving $0.5 \mathrm{~g}$ of commercial chitosan powder into $100 \mathrm{ml}$ of glacial acetic acid solution $(1 \%(\mathrm{v} / \mathrm{v}))$, then the solution was homogenized for \pm 1 hour. The chitosan solution was then sterilized using an autoclave at a temperature of $121^{\circ} \mathrm{C}$ for \pm 10 minutes. The chitosan is then stored in the refrigerator at $4^{\circ} \mathrm{C}$.

\section{Preliminary research}

The preliminary research was done to observe the minimum inhibitor concentration (MIC) of chitosan to Streptomyces sp. GMR- 
22. The concentration of chitosan used in this preliminary study refers to the research of Ghinet et al. (2010) which has been modified in chitosan concentrations of $10 \mu \mathrm{g} / \mathrm{ml}, 25$ $\mu \mathrm{g} / \mathrm{ml}, 50 \mu \mathrm{g} / \mathrm{ml}, 100 \mu \mathrm{g} / \mathrm{ml}, 250 \mu \mathrm{g} / \mathrm{ml}, 500$ $\mu \mathrm{g} / \mathrm{ml}, 750 \mu \mathrm{g} / \mathrm{ml}, 1000 \mu \mathrm{g} / \mathrm{ml}$, and without chitosan as control. The inoculum concentration used was $1 \%(\mathrm{v} / \mathrm{v})$ with the final volume of the medium around $\pm 5 \mathrm{ml}$. The medium was then incubated using an orbital shaker at room temperature with an agitation of $200 \mathrm{rpm}$ for \pm 1 day. Optical Density (OD) of each treatment replication was observed using a spectrophotometer with a wavelength of $600 \mathrm{~nm}$.

Production and isolation of secondary metabolite

Single colony of Streptomyces sp. GMR-22 was pre-cultured on tryptic soy broth (TSB) medium with a volume of $\pm 7 \mathrm{ml}$ and incubated at room temperature for \pm 2 days in an orbital shaker with an agitation speed of $200 \mathrm{rpm}$. Fermentation process was done by inoculating $1 \%(\mathrm{v} / \mathrm{v})$ pre-cultured inoculum in $250 \mathrm{ml}$ flasks containing $100 \mathrm{ml}$ of starch nitrate broth (SNB) medium. Each treatment was added with a sterile chitosan solution with varying final concentrations of chitosan $250 \mu \mathrm{g} / \mathrm{ml}, 500 \mu \mathrm{g} / \mathrm{ml}, 750 \mu \mathrm{g} / \mathrm{ml}$, and 0 as a control (E250, E500, E750 and E0).
Kanamycin $(50 \mathrm{mg} / \mathrm{ml})$ was used as positive control, while sterile TSB medium used as negative control. The medium was then incubated using an orbital shaker at room temperature with an agitation speed of 200 rpm for 10 days. The extraction of secondary metabolites from the fermentation process was carried out by transferring the culture into a $50 \mathrm{ml}$ falcon tube. The sample was then centrifuged at $3500 \mathrm{rpm}$ for 15 minutes to separate the pellets and supernatant. The supernatant was then transferred to a separating funnel, then extracted using ethyl acetate solvent with a ratio of $1: 1(\mathrm{v} / \mathrm{v})$, then shaker for \pm 25 minutes. The extract was then separated into two types of fractions, water fraction and ethyl acetate. The sample extract was put into a rotary evaporator, the water temperature in the water bath was set at $40^{\circ} \mathrm{C}$ with a speed of $100 \mathrm{rpm}$. The sample was allowed to reach a volume of 1-2 $\mathrm{ml}$, then transferred to a $5 \mathrm{ml}$ vial tube. The extract will then be dried using a freeze dryer.

\section{Antibacterial activity assay}

Microdilution assay was conducted according to Balouiri et al. (2016). HPB isolate was inoculated into TSB medium with a volume of $\pm 7 \mathrm{ml}$ incubated at $37^{\circ} \mathrm{C}$ for \pm 24 hours. Extract the water fraction of the metabolite Streptomyces sp. GMR-22 was 
dissolved in sterile distilled water and mixed into TSB medium with a final concentration of $100 \mathrm{mg} / \mathrm{ml}$ with a final volume of $\pm 1 \mathrm{ml}$. The inoculum concentration used for each $\mathrm{BPH}$ was $1 \%(\mathrm{v} / \mathrm{v})$. The medium was then incubated at $37^{\circ} \mathrm{C}$ for \pm 24 hours. Optical Density (OD) was observed using a spectrophotometer with a wavelength of 600 $\mathrm{nm}\left(\mathrm{OD}_{600}\right)$ to determine the effectiveness of antibacterial activity. The antimicrobial activity was described in terms of the percentage of antibacterial effectiveness in the growth of histamine-producing bacteria between negative control and treatment.

\section{RESULTS AND DISCUSSION}

Streptomyces sp.GMR-22 was isolated from cajuput plant rhizosphere soils in Wanagama I Forest UGM Yogyakarta (Nurjasmi et al., 2009). The strain GMR-22 was identified afterward by Alimuddin et al. (2011) by using $16 \mathrm{~S}$ rRNA primer pairs $27 \mathrm{f}$ (5'- AGAGTTTGATCCTGGCTCAG-3') and $\quad 1492 \mathrm{r}$ GGTTACCTTGTTACGACTT-3') and reported as the isolate which possessed the strongest antifungal activity. In this study, we aims to continue the exploration of bioactive compounds produced by Streptomyces sp. GMR-22 and focused on the antibacterial activity against histamine-producing bacteria (HPB). In the same time, we also want to explore the potency of chitosan (chitin derivate) as elicitor compounds.

\section{Preliminary test}

Determination of the concentration of chitosan that will be used as a treatment for the fermentation of Streptomyces sp. GMR22 was done through a preliminary test. Based on Table 1, it can be observed that Streptomyces sp. GMR-22 grown on TSB medium with the addition of chitosan treatment $10 \mu \mathrm{g} / \mathrm{ml}, 25 \mu \mathrm{g} / \mathrm{ml}, 50 \mu \mathrm{g} / \mathrm{ml}, 100$ $\mu \mathrm{g} / \mathrm{ml}, 250 \mu \mathrm{g} / \mathrm{ml}$, and control gave $\mathrm{OD}_{600}$ values in the range of $2.414-2.523$. The $\mathrm{OD}_{600}$ value tends to be high and indicates that the environmental conditions of the medium in the treatment of adding chitosan $10 \mu \mathrm{g} / \mathrm{ml}$ to $250 \mu \mathrm{g} / \mathrm{ml}$ still provide optimal environmental conditions for the growth of Streptomyces sp. GMR-22. Based on Table 1, the addition of chitosan which is first dissolved using $1 \%$ glacial acetic acid still provides an optimal $\mathrm{pH}$ conditions for the growth of Streptomyces. This results was in accordance with Kontro et al. (2005) which reported that several types of Streptomyces grown on various types of medium able to grow at $\mathrm{pH}$ conditions range from 4 - 11.5. 
In addition, it is also assumed that there has been a change in $\mathrm{pH}$ during the mixing process of chitosan solution with TSB medium which affects the protonation mechanism of chitosan, which results in weakening of the antibacterial activity produced by chitosan. Chitosan has a pKa value of around 6.2 - 7.0 which causes chitosan to dissolve in dilute organic acids (Zargar et al., 2015). In this condition, the chitosan amine group will undergo protonation so that it is positively charged to become $\mathrm{NH}^{+}$ions which will affect the antibacterial activity of chitosan (Zargar et al., 2015). Increasing the $\mathrm{pH}$ value due to mixing chitosan with TSB medium resulted in chitosan not being protonated, so that the antibacterial activity of chitosan did not tend to affect the growth of Streptomyces sp. GMR-22. Streptomyces is also reported to have the ability to utilize chitin and its derivatives as a nutrient source by producing chitinase and chitosanase. Streptomyces is able to produce the chitosanase which has a role to hydrolyze the long chain of chitosan into its oligomers so that it can be transported into cells and is useful as a source of carbon and nitrogen (Ghinet et al., 2010).

Based on Table 1 the growth of Streptomyces sp. GMR-22 was a dramatically decrease in the addition of $500 \mu \mathrm{g} / \mathrm{ml}$ chitosan (OD 600 1.129); $750 \mu \mathrm{g} / \mathrm{ml}$ (OD 600 0.030); and $1000 \mu \mathrm{g} / \mathrm{ml}\left(\mathrm{OD}_{600}\right.$ 0.072). This condition indicates that Streptomyces sp. GMR-22 slowly cannot withstand the antibacterial activity of chitosan which causes its growth to be inhibited. The mixing process of chitosan and TSB medium still provides a $\mathrm{pH}$ condition in the $\mathrm{pKa}$ value range of chitosan (6.2 - 7.0) which allows chitosan to undergo protonation so that it still has the ability to be antibacterial 
Table 1. Effect of chitosan concentration on Streptomyces sp. GMR-22 growth

\begin{tabular}{lll}
\hline \multicolumn{1}{c}{ Treatment } & pH & OD600 \\
\hline Control & 7.4 & 2.523 \\
Chitosan $10 \mu \mathrm{g} / \mathrm{ml}$ & 7.3 & 2.458 \\
Chitosan $25 \mu \mathrm{g} / \mathrm{ml}$ & 7.3 & 2.436 \\
Chitosan $50 \mu \mathrm{g} / \mathrm{ml}$ & 7.3 & 2.436 \\
Chitosan $100 \mu \mathrm{g} / \mathrm{ml}$ & 7.2 & 2.414 \\
Chitosan $250 \mu \mathrm{g} / \mathrm{ml}$ & 7.1 & 2.441 \\
Chitosan $500 \mu \mathrm{g} / \mathrm{ml}$ & 6.9 & 1.129 \\
Chitosan $750 \mu \mathrm{g} / \mathrm{ml}$ & 6.7 & 0.03 \\
Chitosan $1000 \mu \mathrm{g} / \mathrm{ml}$ & 6.5 & 0.072 \\
\hline
\end{tabular}

Based on these conditions, the selection of the concentration of chitosan was carried out by referring to the $\mathrm{OD}_{600}$ value which is considered to provide environmental conditions that can stimulate changes in the production of secondary metabolite compounds Streptomyces sp. GMR-22. Secondary metabolites are compounds produced by microorganisms under certain conditions in response to survival. The chitosan treatment that will be used for the main research stage is assumed to create environmental conditions that can threaten the growth of Streptomyces sp. GMR-22. Based on this results, chitosan concentration of $250 \mu \mathrm{g} / \mathrm{ml}, 500 \mu \mathrm{g} / \mathrm{ml}$, and $750 \mu \mathrm{g} / \mathrm{ml}$ were further used as treatment.

\section{Characteristics of secondary metabolite compounds of Streptomyces sp. GMR-22}

The fermentation process was carried out using 3 treatments of chitosan concentration $250 \mu \mathrm{g} / \mathrm{ml}, 500 \mu \mathrm{g} / \mathrm{ml}$, and 750 $\mu \mathrm{g} / \mathrm{ml}$ which were obtained from the preliminary test and 1 control. This process was carried out for 10 days using an orbital shaker with an agitation speed of $200 \mathrm{rpm}$ and incubated at room temperature. During the fermentation process, there was a color change in the SNB medium in each treatment which can be seen in Table 2. In the control 
treatment without the addition of chitosan, the color changes in the medium from initially white to brownish orange. Whereas in the chitosan treatment of $250 \mu \mathrm{g} / \mathrm{ml}, 500$ $\mu \mathrm{g} / \mathrm{ml}$, and $750 \mu \mathrm{g} / \mathrm{ml}$ in general, the color characteristics were not different from the respective treatments which caused the medium to turn yellowish. The change in the color of the medium is caused by the presence of secondary metabolites produced by Streptomyces sp. GMR-22. This color change is also caused by several factors such as temperature, $\mathrm{pH}$, agitation, aeration, and fermentation time during the fermentation process.

The fractionation of secondary metabolites from Streptomyces sp. GMR-22 was carried out using two solvent which were water and ethyl acetate. The ethyl acetate fraction was done with a ratio of $1: 1(\mathrm{v} / \mathrm{v})$ in constant shaking to dissolve the secondary metabolite compound which is semi-polar. The insoluble portion of ethyl acetate hereinafter referred to water fraction. The extract was then concentrated using a rotary evaporator using a temperature of $40^{\circ} \mathrm{C}$ in each of the water and ethyl acetate extracts. Furthermore, the extract is freeze dried to get the dry extract.

Based on Table 2, it can be seen that the appearance of ethyl acetate extract is generally similar in the whole treatment which will produce yellow to orange crystals after freeze dried with a production capacity of $0.10-0.33 \mathrm{~g} / \mathrm{l}$. In water extract, the resulting compound is more yellowish to brownish in color. The treatment of chitosan administration has an effect on changes in the brighter color of fermented products. This may be due to changes in environmental conditions in the SNB medium which affect the response of Streptomyces sp. GMR-22 utilizes available nutrients which also have an impact on the metabolites produced. The production capacity of the compounds obtained from aqueous extracts tends to be greater when compared to ethyl acetate extracts. Based on Table 2 it was shown that the water extract production capacity of the entire treatment was in the range of 12.54 $15.27 \mathrm{~g} / 1$. 
THE POTENCY OF CHITOSAN AS AN ELICITOR ON ANTIBACTERIAL ACTIVITY OF Streptomyces $\mathrm{sp}$. GMR-22 AGAINST HISTAMINE-PRODUCING BACTERIA Mohamad Aji Ikhrami, Jaka Widada, Indun Dewi Puspita and Masagus Muhammad Prima Putra

Table 2. The characteristics of the secondary metabolite extracts of Streptomyces sp. GMR-22

\begin{tabular}{|c|c|c|c|c|}
\hline Fraction & Treatment & Weight (g/l) & Appearance & Color \\
\hline \multirow{4}{*}{ Water } & Control & 14,97 & $\begin{array}{c}\text { Brown crystalline } \\
\text { powder }\end{array}$ & Brownish orange \\
\hline & $250 \mu \mathrm{g} / \mathrm{ml}$ & 15,27 & White fine powder & Yellowish clear \\
\hline & $500 \mu \mathrm{g} / \mathrm{ml}$ & 12,54 & White fine powder & $\begin{array}{l}\text { Yellowish } \\
\text { cloudy }\end{array}$ \\
\hline & $750 \mu \mathrm{g} / \mathrm{ml}$ & 14,44 & White fine powder & $\begin{array}{l}\text { Yellowish } \\
\text { cloudy }\end{array}$ \\
\hline \multirow{4}{*}{$\begin{array}{c}\text { Ethyl } \\
\text { Acetate }\end{array}$} & Control & 0,32 & Orange crystals & Clear \\
\hline & $250 \mu \mathrm{g} / \mathrm{ml}$ & 0,10 & Yellow crystal & Clear \\
\hline & $500 \mu \mathrm{g} / \mathrm{ml}$ & 0,29 & Yellow crystal & Clear \\
\hline & $750 \mu \mathrm{g} / \mathrm{ml}$ & 0,33 & Yellow crystal & Clear \\
\hline
\end{tabular}

Antibacterial activity against histamineproducing bacteria

The antibacterial activity of the secondary metabolite extracts of Streptomyces sp. GMR-22 was performed using microdilution assay with extract concentration $100 \mathrm{mg} / \mathrm{ml}$. Antibacterial activity produced by Streptomyces sp. GMR22 is shown in Table 3.

Table 3. Antibacterial activity of Streptomyces sp. GMR-22 on histamine-producing bacteria

\begin{tabular}{ccccccc}
\hline \multirow{2}{*}{ Tested strain } & \multicolumn{7}{c}{ Percent inhibition (\%) } \\
\cline { 2 - 7 } & Kanamycin & Negative & E0 & E250 & E500 & E750 \\
\hline Morganella morganii TK7 & $99.45^{\mathbf{a}}$ & 0 & $75.69^{\mathbf{c}}$ & $97.29^{\mathbf{a}}$ & $87.91^{\mathbf{b}}$ & $79.61^{\mathbf{c}}$ \\
Citrobacter freundii CK1 & $98.01^{\mathbf{a}}$ & 0 & $97.78^{\mathbf{a}}$ & $97.92^{\mathbf{a}}$ & $99.69^{\mathbf{a}}$ & $58.29^{\mathbf{b}}$ \\
\hline
\end{tabular}

Based on the results, it can be seen that the response of each histamineproducing bacteria used as the test bacteria is different, however, all bacterial tested were grew normally in negative control. Treatment E250 has the highest antibacterial 
activity in every antibacterial activity test carried out on the three types of histamineforming bacteria. E250 extract was effective in inhibiting the growth of Morganella morganii TK7 and Citrobacter freundii CK1 with inhibition percentage values of $97.29 \%$ and $97.92 \%$, respectively and no significant different with positive control. The antibacterial activity of E250 was slightly higher compared to E0. This shows that the addition of $250 \mu \mathrm{g} / \mathrm{ml}$ chitosan might be stimulate Streptomyces sp. GMR-22 to increase the expression of genes that play a role in increasing the antibacterial activity. Based on the preliminary test conducted previously, it can be seen that the addition of $250 \mu \mathrm{g} / \mathrm{ml}$ of chitosan has an OD600 value of 1.129. This absorbance value indicates that the addition of $250 \mu \mathrm{g} / \mathrm{ml}$ of chitosan creates a stress-response condition that can be used by Streptomyces sp. GMR-22 to be able to grow even with stressful conditions that trigger the expression of genes that affect certain metabolite pathways.

Changes in growth environmental conditions can affect the morphology of each Streptomyces life cycle and can affect the production of secondary metabolites. The addition of chitosan dissolved using acetic acid has the potential to affect the $\mathrm{pH}$ conditions of the fermentation medium, besides the antibacterial activity of chitosan can cause a stress response from Streptomyces sp. GMR-22 which might be resulted in the response changes in gene expression produced on producing secondary metabolites during the fermentation process. Ghinet et al. (2010) reported that the addition of different chitosan concentrations could affect morphological changes in Streptomyces lividans TK24 grown on agar medium. Morphological changes in Streptomyces can affect the process of the production of secondary metabolites produced during its life cycle. Viollier et al. (2001) also reported that different $\mathrm{pH}$ conditions affect the growth and development of Streptomyces coelicolor. Chitosan and chitin have the same constituent components, it's just that chitin is dominated by $\mathrm{N}$ acetylglucosamine, while chitosan tends to be composed of glucosamine monomers (Zerger et al., 2015).

To confirm that the antibacterial activity of the extract produced during the fermentation process in the addition of chitosan treatment did not come from the activity of chitosan, an antibacterial activity test of chitosan was also carried out which can be seen in Table 4. 
Table 4. Antibacterial activity of chitosan on histamine-producing bacteria

\begin{tabular}{cccc}
\hline \multirow{2}{*}{ Tested strain } & \multicolumn{3}{c}{ Inhibitory Percentage (\%) } \\
\cline { 2 - 4 } & K250 & K500 & K750 \\
\hline Morganella morganii TK7 & $10.54^{\mathbf{a}}$ & $32.95^{\mathbf{b}}$ & $97.95^{\mathbf{c}}$ \\
Citrobacter freundii CK1 & $74.76^{\mathbf{a}}$ & $77.18^{\mathbf{a}}$ & $93.89^{\mathbf{a}}$ \\
\hline
\end{tabular}

When compared with the results of the antibacterial activity described in Table 3, it can be seen that the antibacterial activity produced between extracts of secondary metabolites and chitosan is not the same. This shows that the antibacterial activity of the secondary metabolite extract is not derived from chitosan, thus indicating that the addition of chitosan during the fermentation process can affect the response of Streptomyces sp. GMR-22 in producing secondary metabolite compounds.

\section{CONCLUSIONS AND SUGGESTIONS}

\section{Conclusions}

Streptomyces sp. GMR-22 has the potential to produce antibacterial compounds that can inhibit the growth of histamineproducing bacteria. The addition of chitosan had an effect on the color change and the characteristics of the extract of secondary metabolite compounds. The addition of chitosan has an effect on the antibacterial activity of secondary metabolites of Streptomyces sp. GMR-22 with the most effective antibacterial activity was found in E250 treatment which inhibited the growth of Morganella morganii TK7 and Citrobacter freundii CK1 with inhibition percentage values of $97.29 \%$ and $97.92 \%$. This shows that chitosan has the potential as an elicitor compound which can influenced the metabolites produced by Streptomyces sp. GMR-22.

\section{Suggestions}

In this research, it is still necessary to test the characterization of the secondary metabolite extracts of Streptomyces $\mathrm{sp}$. GMR-22 to determine the differences in the compound components of each extract produced. In addition, the volume of production of secondary metabolites of Streptomyces sp. GMR-22 needs to be increased so that the optimal amount of extract is obtained for activity testing using a higher concentration. The extraction process of secondary metabolites can use various 
types of solvents to confirm the secondary metabolites of Streptomyces sp. GMR-22 which has antibacterial activity.

\section{REFERENCES}

Abdelmohsen, U. R., T. Grkovic, S. Balasubramanian, M. S. Kamel, R. J. Quinn, \& U. Hentschel. (2015). Elicitation of secondary metabolism in actinomycetes. Biotechnology Advances. 33: 798-811.

Alimuddin, J. Widada, W. Asmara, and Mustofa. (2011). Antifungal production of a strain of Actinomycetes spp. isolated from the rhizospore of cajuput plant: selection and detection of exhibiting activity against tested fungi. Indonesia Journal of Biotechnology. 16(1): 1-10.

Azerang, P. \& S. Sardari. (2017). Bioactive Compound Produced from Actinomycetes-Streptomyces. Nov. Appro. Drug. Des. Dev. 1(3): 1-2.

Balouiri,M., M. Sadiki, and S. K. Ibnsouda. 2016. Methods for in vitro evaluating antimicrobial activity: A review. J. Pharm. Anal. 6 (2): 71-79.

Bentley, S. D., K. F. Chater, A. M. CerdenioTarraga, G. L. Challis, N. R. Thomson, K. D. James, D. E. Harris, M. A. Quail, H. Kieser, D. Harper, A. Bateman, S. Brown, G. Chandra, C.W. Chen, M. Collins, A. Cronin, A. Fraser, A. Gobie, J. Hidalgo, T. Hornsby, S. Howarth, C. H. Huang, T. Kieser, L. Larke, L. Murphy, K. Oliver, S. O’Neil, E. Rabbinowitsch, M. A. Rajandream, K. Rutherford, S. Rutter, K. Seeger, D. Saunders, S. Sharp, R. Squares, K. Taylor, T. Warren, A. Wietzorrek, J. Woodward, B. G. Barrell, J. Parkhill, \& D. A. Hopwood. (2002). Complete genome sequence of the model actinomycete Streptomyces coelicolor A3 (2). Nature 417: 141-147.

Cheng, K., X. Roong, A. A. Pinto-Tomás, M. Fernández-Villalobos, C. MurilloCruz, \& Y. Huang. (2015). Population of genetic analysis of Streptomyces albidoflavus reveals habitat barriers to homologous recombination in the diversification of Streptomyces. Applied and Environmental Microbiology. 81(3): 966 - 975.

Ghinet, M. G., S. Roy, D. Poulin-Laprade, M. Lacomber-Harvey, R. Morosoli, \& R. Brzezinski. (2010). Chitosanase from Streptomyces coelicolor A3 (2): biochemical properties and role in protection against antibacterial effect of chitosan. Biochemical Cell Biology 88: 907-916.

Herdini, C., S. Mubarika, B. Hariwiyanto, N. Wijayanti, A. Hosoyama, A. Yamazoe, H. Nojiri, \& J. Widada. 2017. Secondary bioactive metabolite gene clusters identification of anticandidalproducing Streptomyces sp. GMR-22 isolated from Wanagama Forest as revealed by genome mining approach. Indonesian Journal of Pharmacy 28(1): 26-33.

Kontro, M., U. Lignell, M-R. Hirvonen, \& A. Nevalainen. (2005). pH effects on 10 Streptomyces spp. growth and sporulation depend on nutrients. Lett. Appl. Microbiol. 41(1): 32-38.

Liu, L., L. Qin, S. Hao, R. Lan, B. Xu, Y. Guo, R. Jiang, H. Sun, X. Chen, X. LV, J. Xu, \& C. Zhao. (2020). Lineage, antimicrobial resistance and virulence of Citrobacter spp. Pathogens. 9(195): $1-21$.

Matsuda, K., F. Hasebe, Y. Shiwa, Y. Kanesaki, T. Tomita, H. Yoshikawa, K. Shin-Ya, T. Kuzuyama, \& M. Nishiyama. (2017). Genome Mining of Amino Group Carrier Protein-Mediated 
Machinery: Discovery and Biosynthetic Characterization of a Natural Product with Unique Hydrazone Unit. ACS Chem. Biol. 12(1): 124-131.

Mentari, D., M. Naima, R. Wulansari, J. Widada, T. R. Nuringtyas, T. Wibawa, \& N. Wijayanti. (2019). Pengaruh perbedaan metode ekstraksi metabolit sekunder Streptomyces sp. GMR-22 terhadap toksisitas pada sel BHK-21. Pharmacon: Jurnal Farmasi Indonesia. 16 (1): 1-10.

Nazari, B., M. Kobayashi, A. Saito, A. Hassanisab, K. Miyashita, \& T. Fujii. (2013). Chitin-induced gene expression in secondary metabolic pathway of Streptomyces coelicolor A3 (2) grown in soil. Applied and Environmental Microbiology. 79 (2): 707-713.

Nurjasmi, R., J. Widada, \& Ngadiman. (2009). Diversity of actinomycetes at several forest types in Wanagama I Yogyakarta and their potency as a producer of antifungal compound. Indonesia Journal of Biotechnology. 14 (2): 1196-1205.

Onaka, H. (2017). Novel antibiotic screening methods to awaken silent or cryptic secondary metabolic pathways in actinomycetes. The Journal of Antibiotics 70: 865-870.

Pettit, R. K. (2011). Small-molecule elicitation of microbial secondary metabolites. Microbial Biotechnology. 4 (4): 471-478.

Procópioa, R. E. L., I. R. da Silvaa, M. K. Martinsa, J. L. de Azevedoa, \& J. M. de
Araújob. (2012). Antibiotics produced by Streptomyces (review). Braz. J. Infect. Dis. 16 (5):466-471.

Rigali, S., F. Titgemeyer, S. Barends, S. Mulder, A. W. Thomae, D. A. Hopwood, \& G. P. van Wezel. (2008). Feast or famine: the global regulator DasR links nutrient stress to antibiotic production by Streptomyces. European Molecular Biology Organization. 9(7): 670-675.

Rutledge, P. J., \& G. L. Challis. (2015).

Discovery of microbial natural products by activation of silent biosynthetic gene clusters. Nature 13: $1-15$.

Thong W. L., K. Shin-ya, M. Nishiyama \& T. Kuzuyama. (2018). Discovery of an Antibacterial Isoindolinone-Containing Tetracyclic Polyketide by Cryptic Gene Activation and Characterization of Its Biosynthetic Gene Cluster. ACS Chem. Biol. 13 (9): 2615-2622.

Tyurin A. P., V. A. Alferova \& V. A. Korshun. (2018). Chemical Elicitors of Antibiotic Biosynthesis in Actinomycetes. Microorganisms 6 (2): 1-10.

Viollier, P. H., W. Minas, G. E. Dale, M. Folcher, \& C. J. Thompson. (2001).

Zargar, V., M. Asghari, \& A. Dashti. (2015). A Review on Chitin and Chitosan Polymers: Structure, Chemistry, Solubility, Derivatives, and Applications. Chem. Bio. Eng. 2 (3): 204-226. 